\title{
Long-Term Ouabain Treatment Impairs Vascular Function in Resistance Arteries
}

\author{
Camilla Ferreira Wenceslau $^{\mathrm{a}} \quad$ Ana Paula Davel $^{\mathrm{a}}$ Fabiano Elias Xavier $^{\mathrm{b}}$ \\ Luciana Venturini Rossoni ${ }^{\mathrm{a}}$ \\ ${ }^{a}$ Department of Physiology and Biophysics, Institute of Biomedical Sciences, University of Sao Paulo, Sao Paulo, and \\ ${ }^{b}$ Department of Physiology and Pharmacology, Biological Sciences Center, Federal University of Pernambuco, \\ Recife, Brazil
}

\section{Key Words}

Ouabain-induced hypertension $\cdot$ Resistance arteries

Oxidative stress $\cdot$ COX-2 $\cdot$ Pro-inflammatory cytokines

\begin{abstract}
Background/Aims: The purpose of this study was to examine the cardiovascular effects of long-term ouabain treatment at different time points. Methods: Systolic blood pressure (SBP) was measured by tail-cuff method in male Wistar rats treated with ouabain (approx. $8.0 \mu \mathrm{g} \cdot \mathrm{day}^{-1}$ ) or vehicle for 5, 10 and 20 weeks. Afterwards, vascular function was assessed in mesenteric resistance arteries (MRA) using a wire myograph. ROS production and COX-1 and COX-2, TNF- $\alpha$, and IL- 6 protein expression were investigated. Results: SBP was increased by ouabain treatment up to the 6 th week and remained stable until the 20th week. However, noradrenaline-induced contraction increased only in MRA in rats treated with ouabain for 20 weeks. NOS inhibition and endothelium removal increased the noradrenaline response, but to a smaller magnitude in MRA in the ouabain group. Moreover, inhibition of COX-2 or incubation with superoxide dismutase restores noradrenaline-induced contraction in the 20 -week ouabain group to control levels. ROS production as
\end{abstract}

well as COX-2, IL-6 and TNF- $\alpha$ protein expression increased in MRA in this group. Conclusion: Although ouabain treatment induced hypertension in all groups, a larger noradrenaline induced contraction was observed over 20 weeks of treatment. This vascular dysfunction was related to COX-2derived prostanoids and oxidative stress, increased proinflammatory cytokines and reduced NO bioavailability.

Copyright $\odot 2011$ S. Karger AG, Basel

\section{Introduction}

Ouabain is an adrenal- and hypothalamus-derived circulating steroid hormone in humans and animals, which is produced in response to volume expansion, angiotensin II and/ or adrenocorticotropic hormone stimulation [1-4]. It participates in fluid homeostasis and plays a role in the long-term regulation of $\mathrm{Na}^{+}$and $\mathrm{K}^{+}$. In addition, ouabain has also been implicated in the control of many functions involving the cardiovascular and nervous systems [2-4], as well as in the pathogenesis of chronic renal failure, hyperaldosteronism, congestive heart failure and hypertension $[2,5,6]$.

\section{KARGER}

Fax +41613061234 E-Mail karger@karger.ch www.karger.com (c) 2011 S. Karger AG, Basel

$1018-1172 / 11 / 0484-0316 \$ 38.00 / 0$

Accessible online at:

www.karger.com/jvr
Dr. Luciana V. Rossoni

Departamento de Fisiologia e Biofísica

Instituto de Ciências Biomédicas, Universidade de São Paulo

Av. Professor Lineu Prestes, 1524, sala 225, São Paulo, SP 05508-900 (Brazil)

Tel. +55 113091 7243, Fax +55 113091 7285, E-Mail lrossoni@ icb.usp.br 
Treatment with ouabain (or its structurally related analogs) for 2-5 weeks leads to the development of hypertension in rats [7-14]. This is associated with increased sympathetic tone [15-17] and peripheral adjustments in the vascular system $[8-14,18,19]$. Hypertension induced by 5 weeks of ouabain treatment is accompanied by an increase in vasodilator endothelium-derived factors, which act to reduce the vasoconstrictor response to $\alpha_{1}$ adrenergic stimulation and increase the activity of the $\mathrm{Na}^{+} \mathrm{K}^{+}$-ATPase in conductance vessels [9-12]. These responses are mediated by an increase in nitric oxide (NO) production, which is thought to be related to overexpression of the eNOS and nNOS isoforms of NO synthase [10, 11]. However, in mesenteric resistance arteries (MRA), ouabain-induced hypertension did not alter the vasoconstrictor response to noradrenaline [12].

Although it is clear that ouabain induces hypertension, it appears that functional changes in the vasculature attempt to counteract the development of hypertension. Exceptions have been observed in the renal artery and vasa recta, as Kimura et al. [8] described an increase in contractile responses and Cao et al. [20] demonstrated endothelial dysfunction. Nevertheless, all these mechanisms were elucidated in animals exposed to a treatment period of 2-5 weeks. In line with these studies, ouabain treatment produces a progressive increase in blood pressure until the 5th week of treatment, but no studies have addressed what happens to blood pressure and vascular function beyond this treatment period.

In view of that, we determined the effect of long-term ouabain treatment on the blood pressure of Wistar rats at different time points, 10 and 20 weeks, and compared the effects with those observed in 5-week ouabain-treated rats. Furthermore, we analyzed if potential time-dependent alterations could occur on the vascular function of resistance arteries, since these arteries are the main control sites of peripheral vascular resistance and consequently of blood pressure. Special attention was paid to the contribution of endothelial factors, oxidative stress and pro-inflammatory cytokines in the altered vascular response.

\section{Methods}

\section{Animal Housing}

Six-week-old male Wistar rats were obtained from colonies maintained at the Animal House of the Institute of Biomedical Sciences of University of Sao Paulo. Rats were housed in constant room temperature, humidity and light cycles (12:12 h light-dark), with free access to standard rat chow and tap water. The investi- gation conformed to the Guide for the Care and Use of Laboratory Animals published by the US National Institutes of Heath (NIH publication No. 85-23, revised 1996) and with the guidelines of the Committee on Care and Use of Laboratory Animal Resources of the Institute of Biomedical Sciences of the University of Sao Paulo.

Rats were divided into 6 experimental groups: vehicle (VHE) and ouabain-treated rats (OUA, approx. $8.0 \mu \mathrm{g} \cdot \mathrm{day}^{-1}$, subcutaneously) during 5,10 or 20 weeks. Animals were anesthetized with a mixture of ketamine, xylazine and acetopromazin (64.9, 3.2 and $0.78 \mathrm{mg} \cdot \mathrm{kg}^{-1}$, respectively, intraperitoneally). A small incision was then made in the back of the neck to implant a subcutaneous controlled time-released pellet (Innovative Research of America, Sarasota, Fla., USA) containing ouabain $(0.5 \mathrm{mg})$ or VHE, as previously described $[9-13,15,21]$. Systolic blood pressure (SBP) was measured by the tail-cuff method (LE 5001; Panlab s.I. Barcelona, Spain) before the start of treatment and every week during treatment.

Vascular Reactivity Measurements

After 5, 10 or 20 weeks of treatment, rats were anesthetized with a mixture of ketamine, xylazine and acetopromazin, and sacrificed by exsanguination. The mesenteric arcade was then carefully removed. Third-order mesenteric arteries [internal diameter; 5 weeks: VHE: $258 \pm 5.63(\mathrm{n}=15)$ versus OUA: $267 \pm$ $3.97 \mu \mathrm{m}(\mathrm{n}=15)$; 10 weeks: VHE: $255 \pm 5.01(\mathrm{n}=11)$ versus OUA: $263 \pm 4.52 \mu \mathrm{m}(\mathrm{n}=17) ; 20$ weeks: VHE: $274 \pm 4.94(\mathrm{n}=24)$ versus OUA: $273 \pm 5.01 \mu \mathrm{m}(\mathrm{n}=27)$, t test, $\mathrm{p}>0.05$ ] were removed and cleaned of surrounding tissue in cold Krebs-Henseleit solution (KHS, in mmol/l): $\mathrm{NaCl} 118 ; \mathrm{KCl} 4.7 ; \mathrm{NaHCO}_{3} 25 ; \mathrm{CaCl}_{2} .2 \mathrm{H}_{2} \mathrm{O}$ 2.5; $\mathrm{KH}_{2} \mathrm{PO}_{4} 1.2 ; \mathrm{MgSO}_{4} .7 \mathrm{H}_{2} \mathrm{O}$ 1.2; EDTA 0.01; glucose 11. Segments ( $2 \mathrm{~mm}$ in length) were mounted in a small vessel myograph chamber (Danish Myo Tech, model 610M; JP-Trading I/S) for isometric tension recordings, as described previously [12, 22]. Briefly, two steel wires ( $40 \mu \mathrm{m}$ diameter) were introduced through the lumen of the segments and mounted according to the method described by Mulvany and Halpern [22]. After a 15-min equilibration period in oxygenated $\mathrm{KHS}$ at $37^{\circ} \mathrm{C}$ and $\mathrm{pH}$ 7.4, segments were stretched to their optimal lumen diameter for active tension development. This was determined based on the internal circumference/wall tension ratio of the segments by setting the internal circumference, $\mathrm{L}_{0}$, to $90 \%$ of what the vessels would have if they were exposed to a passive tension equivalent to that produced by a transmural pressure of $100 \mathrm{~mm} \mathrm{Hg}\left(\mathrm{L}_{100}\right)$ [22]. The diameter $\left(\mathrm{I}_{1}\right)$ was determined according to the equation $\mathrm{I}_{1}=\mathrm{L}_{1} / \pi$, using specific software for normalization of resistance arteries (DMT Normalization Module; ADInstruments). Segments were washed with KHS and left to equilibrate for $30 \mathrm{~min}$. Vessel contractility was then tested by an initial exposure to a high- $\mathrm{K}^{+}(120 \mathrm{mmol} / \mathrm{l})$ solution.

\section{Experimental Protocols}

Endothelium-dependent relaxations were studied by evaluating relaxations to acetylcholine $(0.01 \mathrm{nmol} / \mathrm{l}$ to $30 \mu \mathrm{mol} / \mathrm{l})$ in arteries precontracted with a concentration of 9,11 -dideoxy-11 $\alpha, 9 \alpha$ epoxymethanoprostaglandin $\mathrm{F}_{2} \alpha$, (U-46619, a thromboxane $\mathrm{A}_{2}$ mimetic) to induce $75-100 \%$ of the contraction induced by $\mathrm{KCl}$ $(120 \mathrm{mmol} / \mathrm{l})$. After $30 \mathrm{~min}$, concentration-response curves to noradrenaline $(10 \mathrm{nmol} / \mathrm{l}$ to $30 \mu \mathrm{mol} / \mathrm{l})$ were performed in the absence (E-) and presence (E+) of the endothelium. The endothe- 
lium was removed by rubbing the lumen using a human hair previously washed with ethanol (70\%) and then with KHS. The endothelium was considered intact if the arteries relaxed more than $80 \%$ to acetylcholine, while endothelial denudation was confirmed by less than $10 \%$ relaxation. In another set of experiments using E+ rings, we evaluated the effects of the nonselective inhibitor of NOS isozymes, N $\omega$-nitro-L-arginine methyl ester (LNAME, $100 \mu \mathrm{mol} / \mathrm{l})$, the nonselective inhibitor of COX, indomethacin (Indo, $10 \mu \mathrm{mol} / \mathrm{l})$, the selective COX-2 inhibitor, N-(2cyclohexyloxy-4-nitrophenyl) methansulfonamide (NS-398, 10 $\mu \mathrm{mol} / \mathrm{l})$, the thromboxane $\mathrm{A}_{2}$ synthesis inhibitor and prostaglandin $\mathrm{H}_{2}$ /thromboxane $\mathrm{A}_{2}$ receptor antagonist, ridogrel ( $\left.1 \mu \mathrm{mol} / \mathrm{l}\right)$, the superoxide dismutase (SOD, $150 \mathrm{U} / \mathrm{ml}$ ), or the hydrogen peroxide scavenger, catalase $(1,000 \mathrm{U} / \mathrm{ml})$. All drugs were added 30 min before the concentration response curve to noradrenaline and were then maintained throughout the entire experiment.

\section{ROS Measurement in MRA and the Role of COX-2 in the} Synthesis of ROS

The oxidative fluorescent dye hydroethidine (Invitrogen, Carlsbad, Calif., USA) was used to evaluate the in situ production of ROS as previously described [23]. Transverse sections (7 $\mu \mathrm{m})$ of frozen MRA were collected on glass slides and equilibrated for $10 \mathrm{~min}$ in phosphate buffer in a light-protected humidified chamber at $37^{\circ} \mathrm{C}$. Fresh buffer containing hydroethidine $(5 \mu \mathrm{mol} / \mathrm{l})$ in the absence or presence of specific inhibitor of COX-2 (NS-398, 10 $\mu \mathrm{mol} / \mathrm{l}$ ) was topically applied to each tissue section and a coverslip placed on top. Slides were incubated in a light-protected humidified chamber at $37^{\circ} \mathrm{C}$ for $30 \mathrm{~min}$. Negative control sections received the same volume of phosphate buffer but in the absence of hydroethidine. After this period, slides were viewed on an optical microscope (Axioskop; Zeiss) equipped with a filter to rodamin and a camera (ZVS-3C75DE; Zeiss), using an objective for fluorescence at $20 \times$. Three different areas of each section were analyzed for the presence of ROS by examination of the regions marked with red fluorescence from the oxidation products of dihydroethidium (DHE).

\section{Western Blot Analysis}

Proteins $(75 \mu \mathrm{g})$ were extracted from third-order branches of the mesenteric artery using a RIPA Lysis Buffer (Upstate). Samples were electrophoretically separated using 7.5 or $12 \%$ SDSPAGE and transferred to polyvinylidene difluoride membranes (Amersham) overnight at $4^{\circ} \mathrm{C}$ using a Mini Trans-Blot Cell system (Bio-Rad) containing $25 \mathrm{mmol} / \mathrm{l}$ Tris, $190 \mathrm{mmol} / \mathrm{l}$ glycine, $20 \%$ methanol and $0.05 \%$ SDS as described previously $[10-12,21]$.

Membranes were blocked with 5\% nonfat dry milk to prevent nonspecific antibody binding and then incubated overnight at $4{ }^{\circ} \mathrm{C}$ with a primary antibody raised against anti-eNOS $(1: 1,000$ dilution; Transduction Laboratories), anti-COX-1 (1:1,000 dilution; Chemicon), anti-COX-2 (2.5 $\mu \mathrm{g} / \mathrm{ml}$ dilution; Upstate), antiIL-1 $\beta$ (1:1,500 dilution; BioLegend), anti-IL-6 (1:1,000 dilution; Abcam) and anti-TNF- $\alpha$ (1:1,500 dilution; BioLegend). Membranes were washed $(10 \mathrm{mmol} / 1$ Tris, $100 \mathrm{mmol} / \mathrm{l} \mathrm{NaCl}$ and $0.1 \%$ Tween 20), and then incubated with peroxidase-conjugated antimouse IgG antibody (1:1,500 dilution; Bio-Rad) for eNOS, peroxidase-conjugated anti-goat IgG antibody (1:15,000 dilution; Jackson ImmunoResearch) for COX-2, peroxidase-conjugated antiArmenian hamster IgG (1:3,000; Jackson ImmunoResearch) for IL- $1 \beta$ and TNF- $\alpha$, or with peroxidase conjugated anti-rabbit IgG
(1:2,000; KPL) for IL-6 and COX-1. Membranes were thoroughly washed, before detecting the immunocomplexes with an enhanced horseradish peroxidase-luminol chemiluminescence system (ECLPlus; Amersham) and subjecting the membrane to autoradiography (Hyperfilm ECL; Amersham). The same membrane was then stripped and used to determine $\alpha$-actin protein expression using the monoclonal antibody anti- $\alpha$-actin $(1: 30,000$ dilution; Sigma). Expression of $\alpha$-actin was then used to normalize the expression of eNOS, COX-1, COX-2, IL-1 $\beta$, IL- 6 and TNF$\alpha$ in each sample. Human umbilical vein endothelial cells were used as positive controls for eNOS and lungs of rats previously activated with lipopolysaccharide were used as positive controls for COX-1, COX-2, IL-1 $\beta$, IL- 6 and TNF- $\alpha$.

\section{Drugs}

Stock solutions of noradrenaline hydrochloride, acetylcholine chloride, $\mathrm{N} \omega$-nitro-L-arginine methyl ester, indomethacin, ridogrel, SOD, catalase, U-46619 (Sigma) and NS-398 (CalbiochemNovabiochem $\mathrm{GmbH}$ ) were prepared in distilled water. Indomethacin was dissolved in $0.1 \mathrm{~mol} / 1$ TRIS (hydroximethyl aminomethane) buffer, while ridogrel was dissolved in saline containing $\mathrm{Na}_{2} \mathrm{CO}_{3}(2 \%)$ plus $\mathrm{NaOH}(40 \mathrm{mmol} / \mathrm{l})$ and $\mathrm{U}-46619$ and NS-398 were dissolved in dimethyl sulfoxide.

\section{Statistical Analysis}

All values are expressed as the mean response \pm SEM. The maximal contractile response to noradrenaline $\left(\mathrm{E}_{\text {max }}\right)$ was expressed as percentage of the maximal contraction induced by $\mathrm{KCl}$ $(120 \mathrm{mmol} / \mathrm{l})$. The negative log of the agonist concentrations resulting in $50 \%$ of the maximum response $\left(\mathrm{pD}_{2}\right)$ was calculated from concentration-response curves by nonlinear regression analysis of the curve using the computer-based fitting program Graphpad Prism (San Diego, Calif., USA). Protein expression of eNOS, COX-1, COX-2, IL-1 $\beta$, IL- 6 and TNF- $\alpha$ was expressed as a ratio of the optical density for each protein against $\alpha$-actin.

Results were analyzed using the unpaired Student's t test or by two-way ANOVA, as appropriate. When ANOVA showed a significant effect of treatment, Bonferroni's post hoc test was used to compare individual means. Differences were considered statistically significant at $\mathrm{p}<0.05$.

\section{Results}

\section{Systolic Blood Pressure}

Ouabain induced a progressive increase in SBP from the 1st week of treatment, in comparison to VHE-treated animals (fig. 1). At the 6th week of ouabain treatment, SBP values reached a plateau, which then remained stable until the 20th week (fig. 1). The weight gain was similar in each group after 5, 10 or 20 weeks of treatment [5 weeks: VHE: $123 \pm 4(\mathrm{n}=10)$ versus OUA: $113 \pm 4 \mathrm{~g}$ ( $\mathrm{n}=10)$; 10 weeks: VHE: $162 \pm 8(\mathrm{n}=10)$ versus OUA: $165 \pm 7 \mathrm{~g}(\mathrm{n}=10) ; 20$ weeks: VHE: $205 \pm 9(\mathrm{n}=10)$ versus OUA: $219 \pm 8 \mathrm{~g}(\mathrm{n}=10)$; t test, $\mathrm{p}>0.05$ ]. 


\section{Vascular Reactivity Study}

$\mathrm{KCl}(120 \mathrm{mmol} / \mathrm{l})$ evoked similar contractions in MRA from VHE and OUA rats in the three periods of treatment [5 weeks: VHE: $2.53 \pm 0.11(\mathrm{n}=15)$ versus OUA: $2.32 \pm 0.09 \mathrm{mN} / \mathrm{mm}(\mathrm{n}=15) ; 10$ weeks: VHE: $2.60 \pm$ $0.12(\mathrm{n}=11)$ versus OUA: $2.69 \pm 0.14 \mathrm{mN} / \mathrm{mm}(\mathrm{n}=17)$; 20 weeks: VHE: $2.77 \pm 0.16(\mathrm{n}=24)$ versus OUA: $2.84 \pm$ $0.14 \mathrm{mN} / \mathrm{mm}(\mathrm{n}=27)$; $\mathrm{t}$ test, $\mathrm{p}>0.05]$. Similarly, relaxation to acetylcholine was not different between MRA from VHE and OUA rats in any of the groups studied (fig. 2a-c). However, chronic treatment with ouabain promoted an increase in the contractile response to noradrenaline in a time dependent manner (fig. $2 \mathrm{~d}-\mathrm{f}$ ). While both 5 and 10 weeks of ouabain treatment did not alter the noradranaline-induced contraction in MRA [fig. $2 \mathrm{~d}$, e; $\mathrm{pD}_{2}$ : 5 weeks: VHE: $5.97 \pm 0.06(\mathrm{n}=15)$ versus OUA: $5.94 \pm 0.07(\mathrm{n}=15) ; 10$ weeks: VHE: $6.01 \pm 0.08(\mathrm{n}=11)$ versus OUA: $5.92 \pm 0.08(\mathrm{n}=17) ; \mathrm{t}$ test, $\mathrm{p}>0.05$; $\mathrm{E}_{\text {max }}$ : 5 weeks: VHE: $178 \pm 6.65(\mathrm{n}=15)$ versus OUA: $173 \pm$ $5.45 \% \mathrm{KCl}(\mathrm{n}=15) ; 10$ weeks: VHE: $166 \pm 5.15(\mathrm{n}=11)$ versus OUA: $163 \pm 5.20 \% \mathrm{KCl}(\mathrm{n}=17)$; t test, $\mathrm{p}>0.05$ ], 20 weeks of treatment significantly increased both $\mathrm{E}_{\max }$ and $\mathrm{pD}_{2}$ (fig. 2f; table 1).

Since the ouabain treatment for minor periods ( 5 and 10 weeks) had no effect on vascular function in MRA, the experimental protocols described below were performed only in vessels taken from VHE and OUA rats for 20 weeks.

In order to analyze the role of the endothelium and endothelium-derived nitric oxide in noradrenaline responses, experiments were performed in the absence of endothelium or in the presence of the NOS inhibitor (LNAME, $100 \mu \mathrm{mol} / \mathrm{l})$. In both groups, noradrenaline-induced contraction was potentiated by endothelium removal or NOS inhibition; however, this potentiation was smaller in MRA from OUA rats (fig. $3 \mathrm{a}$, b; table 1).

To assess the contribution of superoxide anions to noradrenaline-induced contraction, arteries were incubated with SOD $(150 \mathrm{U} / \mathrm{ml})$. In vessels from OUA rats, pretreatment with SOD resulted in a decrease in $\mathrm{E}_{\max }$ without significant changes in the $\mathrm{pD}_{2}$ to noradrenaline (fig. $3 \mathrm{c}$; table 1), an effect that was not further modified by coincubation with SOD and catalase (table 1). In vessels from VHE rats, the response to noradrenaline remained unaltered in the presence of SOD or SOD plus catalase (fig. 3c; table 1).

The COX-1/2 inhibitor indomethacin $(10 \mu \mathrm{mol} / \mathrm{l})$ and the specific COX-2 inhibitor NS-398 $(10 \mu \mathrm{mol} / \mathrm{l})$ had no influence on noradrenaline-induced constriction of arteries from VHE rats (fig. 4a; table 1), but re-

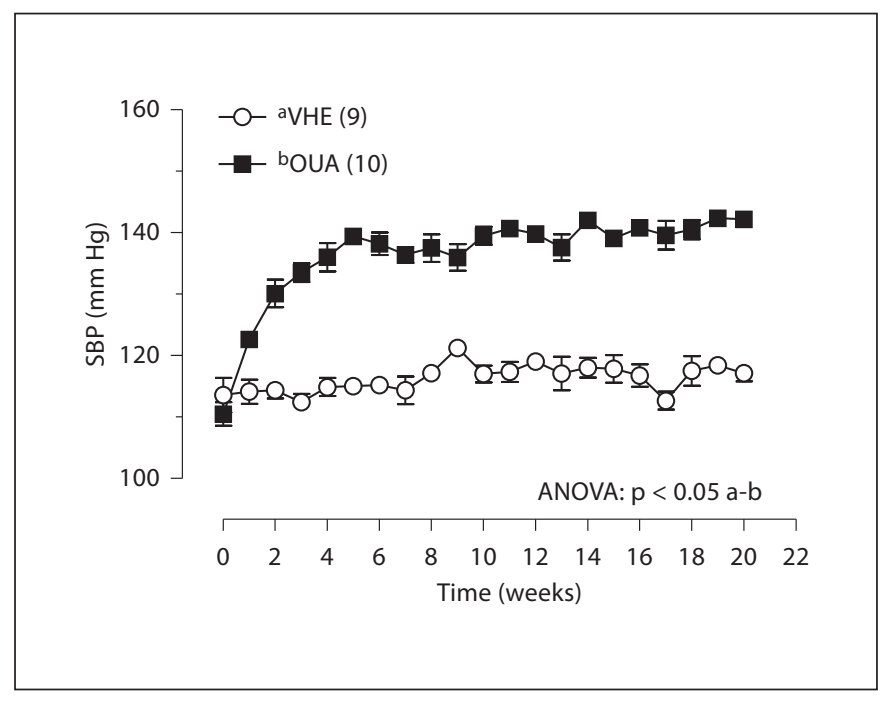

Fig. 1. Values of SBP in VHE or OUA-treated rats during 20 weeks. Number of rats used is indicated in parentheses. Results are expressed as means \pm SEM for the number of animals used.

duced constriction of arteries from OUA rats (fig. 4a; table 1). Pre-incubation of vessels with ridogrel, a TxA synthase inhibitor and $\mathrm{PGH}_{2} / \mathrm{TxA}_{2}$ receptor antagonist, reduced both the $\mathrm{E}_{\text {max }}$ and the $\mathrm{pD}_{2}$ of the noradrenaline response in segments from OUA rats, but had no influence on the response of MRA from VHE rats (fig. $4 \mathrm{~b}$; table 1).

\section{Western Blot Analysis}

Protein expression of eNOS [eNOS/ $\alpha$-actin: VHE: 0.65 \pm 0.09 versus OUA: $0.65 \pm 0.05(n=6)$; $t$ test, $p>0.05$, COX-1 and IL-1 $\beta$ was similar in MRA from VHE and OUA-treated rats for 20 weeks (fig. 5a, c). However, in MRA from OUA group, protein expression of COX-2, IL- 6 and TNF- $\alpha$ was greater when compared to the VHE group (fig. 5b, d, e).

\section{ROS Measurement in MRA}

An increase in ethidium bromide fluorescence was observed in MRA from OUA-treated rats for 20 weeks in comparison to VHE rats (fig. 6). Additionally, incubation with COX-2 inhibitor (NS-398, $10 \mu \mathrm{mol} / \mathrm{l}$ ) was able to decrease the ethidium bromide fluorescence in MRA from OUA-treated rats to levels similar to those observed in the VHE group (fig. 6). Moreover, incubation with NS398 did not change the ethidium bromide fluorescence in arteries from the VHE group (fig. 6). 


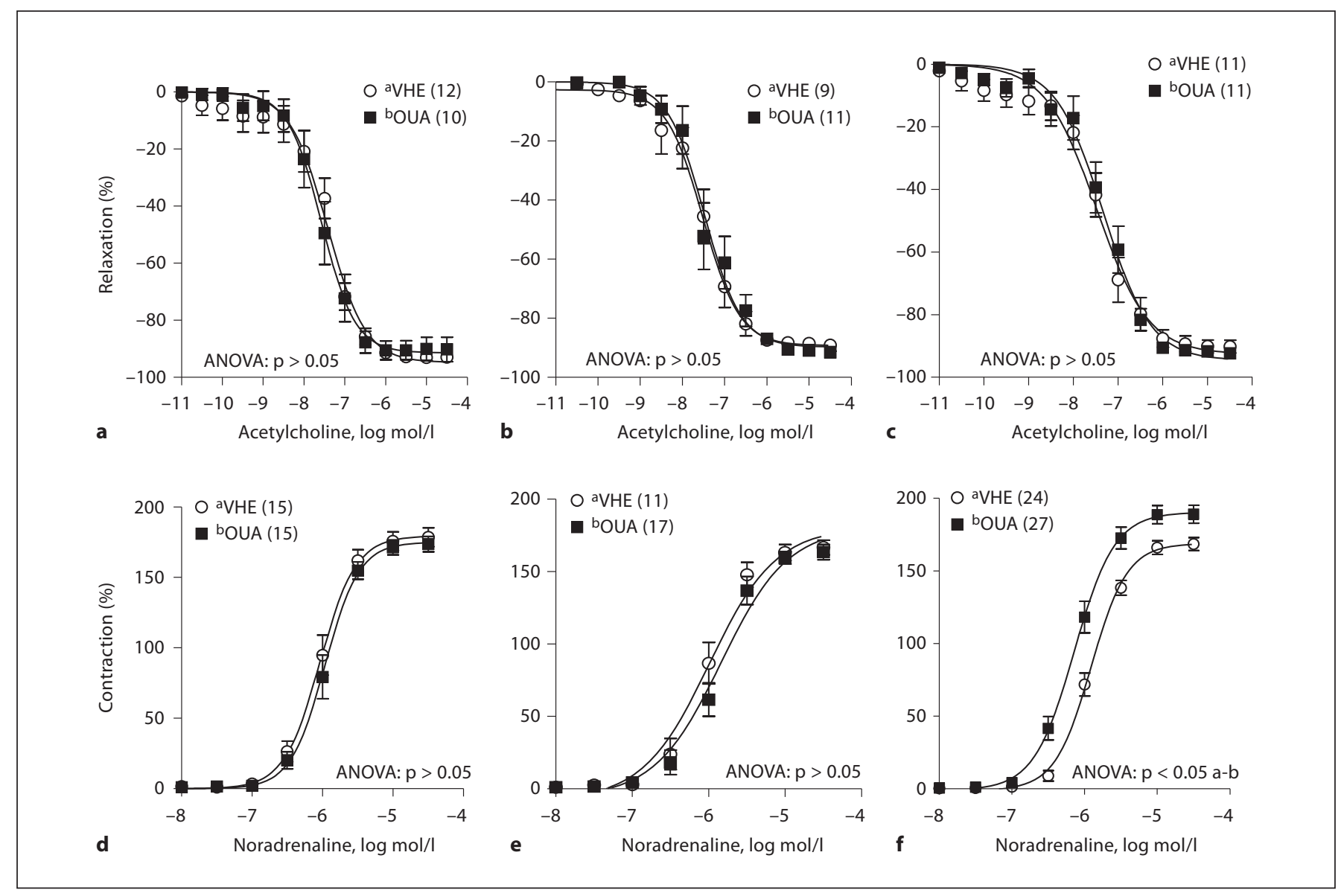

Fig. 2. Endothelium-dependent relaxation to acetylcholine $(\mathbf{a}-\mathbf{c})$ and contractile responses to noradrenaline (d-f) in MRA from VHE and OUA-treated rats for $5(\mathbf{a}, \mathbf{d}), 10(\mathbf{b}, \mathbf{e})$ and $20(\mathbf{c}, \mathbf{f})$ weeks. Number of rats is indicated in parentheses. Results are expressed as means \pm SEM for the number of animals used.

Table 1. Maximum response and sensitivity

\begin{tabular}{llllll}
\hline & \multicolumn{2}{ll}{$\mathrm{pD}_{2}$} & & \multicolumn{2}{c}{$\mathrm{E}_{\max } \%$} \\
\cline { 2 - 3 } \cline { 5 - 6 } & $\mathrm{VHE}$ & $\mathrm{OUA}$ & $\mathrm{VHE}$ & OUA \\
\hline E+ & $5.92 \pm 0.04(24)$ & $6.14 \pm 0.05(27)^{*}$ & & $169 \pm 4.57(24)$ & $190 \pm 6.25(27)^{*}$ \\
E- & $6.66 \pm 0.08(7)^{+}$ & $6.65 \pm 0.06(9)^{+}$ & & $190 \pm 9.82(7)^{+}$ & $197 \pm 10.71(9)$ \\
L-NAME & $6.70 \pm 0.05(11)^{+}$ & $6.53 \pm 0.06(12)^{+}$ & & $201 \pm 12.28(11)^{+}$ & $204 \pm 17.77(12)$ \\
SOD & $5.95 \pm 0.13(6)$ & $5.97 \pm 0.13(6)$ & & $166 \pm 12.80(6)$ & $164 \pm 5.20(6)^{+}$ \\
SOD plus CAT & $5.75 \pm 0.13(7)$ & $5.92 \pm 0.11(7)$ & & $180 \pm 7.76(7)$ & $171 \pm 4.87(7)^{+}$ \\
INDO & $6.01 \pm 0.07(6)$ & $6.05 \pm 0.09(6)$ & & $170 \pm 16.85(6)$ & $152 \pm 22.54(6)^{+}$ \\
NS-398 & $5.82 \pm 0.14(4)$ & $5.69 \pm 0.05(5)^{+}$ & & $163 \pm 16.23(4)$ & $158 \pm 6.52(5)^{+}$ \\
Ridogrel & $6.02 \pm 0.08(7)$ & $5.80 \pm 0.09(7)^{+}$ & & $176 \pm 7.61(7)$ & $159 \pm 9.34(7)^{+}$ \\
\hline
\end{tabular}

Maximum response $\left(\mathrm{E}_{\max }\right)$ and sensitivity $\left(\mathrm{pD}_{2}\right)$ to noradrenaline of endothelium denudation (E-) or intact (E+) MRA incubated with L-NAME, SOD, SOD plus catalase (CAT), indomethacin (INDO), N-[2-(cyclohexyloxy)-4-nitrophenyl]-methanesulfonamide (NS-398) or ridogrel from vehicle (VHE) and ouabain (OUA)-treated rats for 20 weeks. Results are expressed as means \pm SEM for the number of animals used. Number of rats is indicated in parentheses. $t$ test: ${ }^{*} \mathrm{p}<0.05$ versus VHE; ${ }^{+} \mathrm{p}<0.05$ versus E+. 


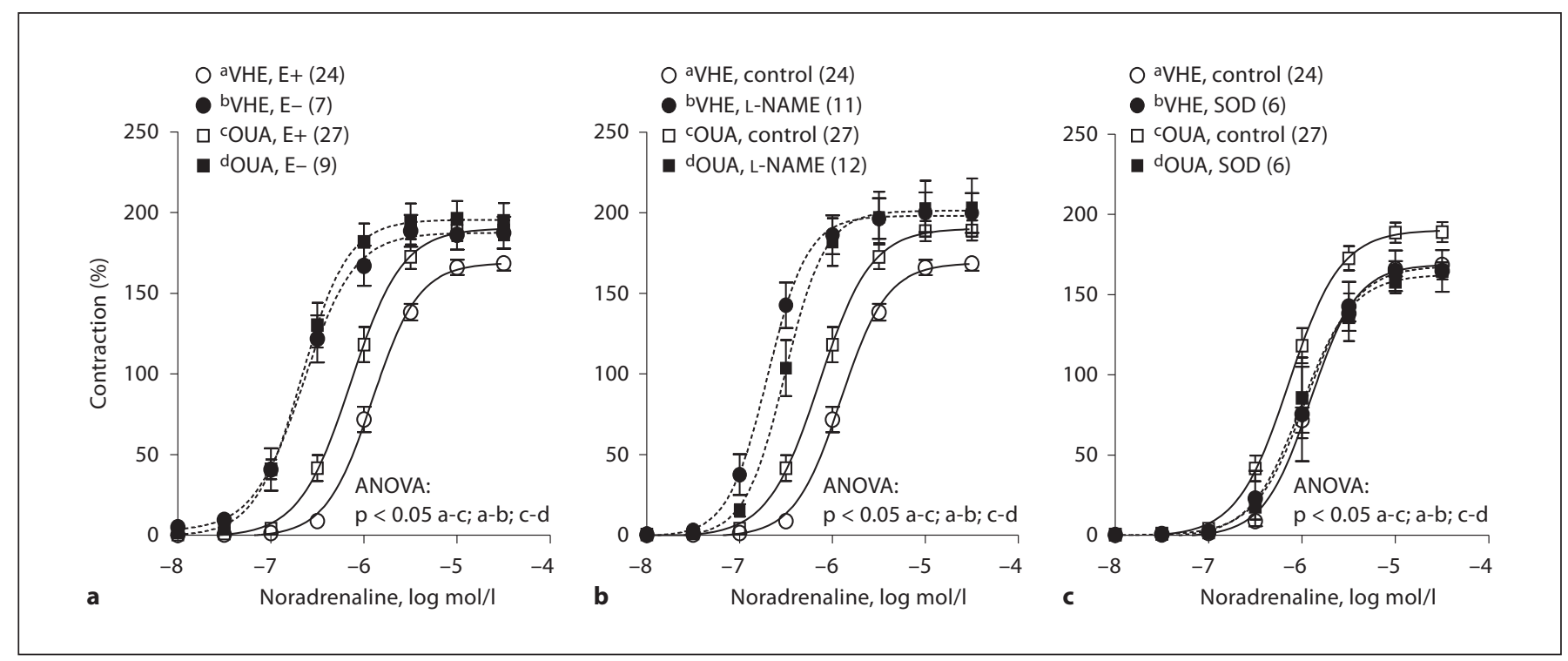

Fig. 3. Effect of endothelium denudation (E-; a), and L-NAME (b) or SOD (c) incubation on the contraction induced by noradrenaline in MRA from VHE and OUA-treated rats for 20 weeks. Number of rats is indicated in parentheses. Results are expressed as means \pm SEM for the number of animals used.

Fig. 4. Effect of NS-398 (a) or ridogrel (b) incubation on the contraction induced by noradrenaline in MRA from VHE and OUA-treated rats for 20 weeks. Number of rats is indicated in parentheses. Results are expressed as means \pm SEM for the number of animals used.

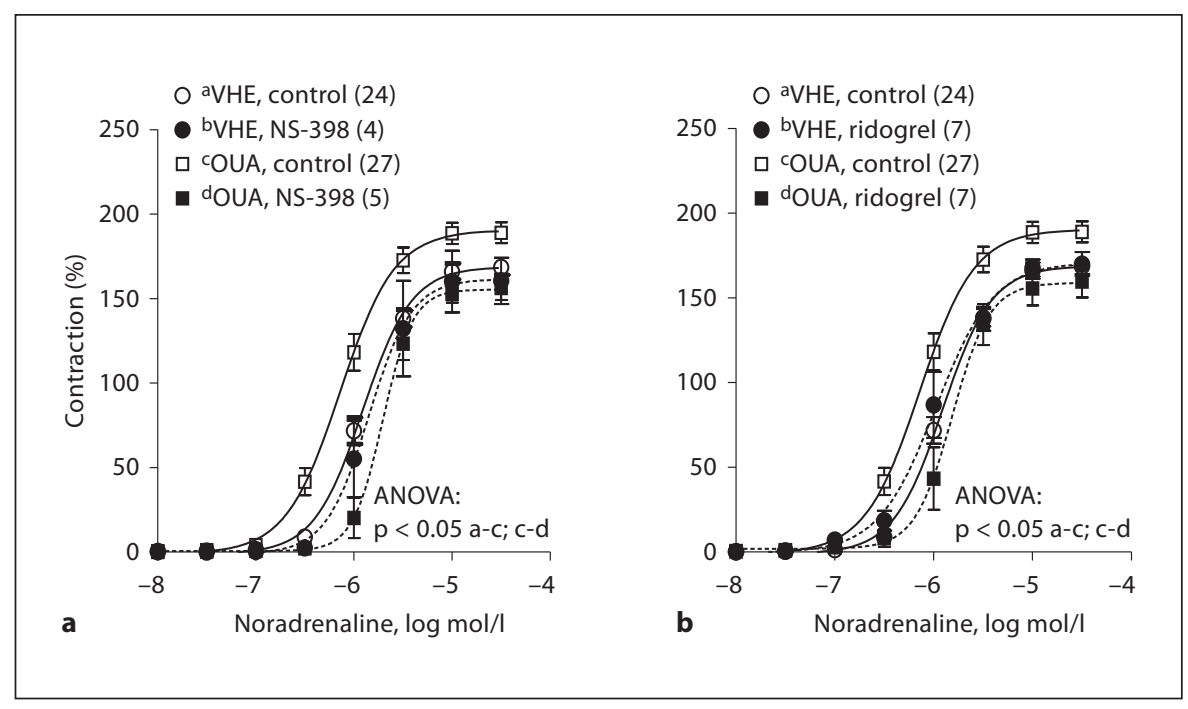

\section{Discussion}

Increasing evidence indicates that endogenous ouabain is able to modulate blood pressure $[2,3]$. Various studies have demonstrated that exposure to ouabain for 2-5 weeks leads to the development of hypertension, but no studies have demonstrated a plateau in blood pressure following this treatment period [7-14, 24]. Our data show for the first time that the maximal hypertensive effect of small doses of ouabain is reached within 6 weeks of treatment, and that this hypertension is maintained over 20 weeks of exposure to the glycoside hormone.

Ouabain-induced hypertension involves central mechanisms associated with increased sympathetic tone $[16,17]$ and peripheral adjustments $[9-14,18-20]$. In the initial stages of hypertension induced by chronic ouabain treatment, the contractile response to phenylephrine in MRA remained unchanged [19]. In addition, Xavier et al. 


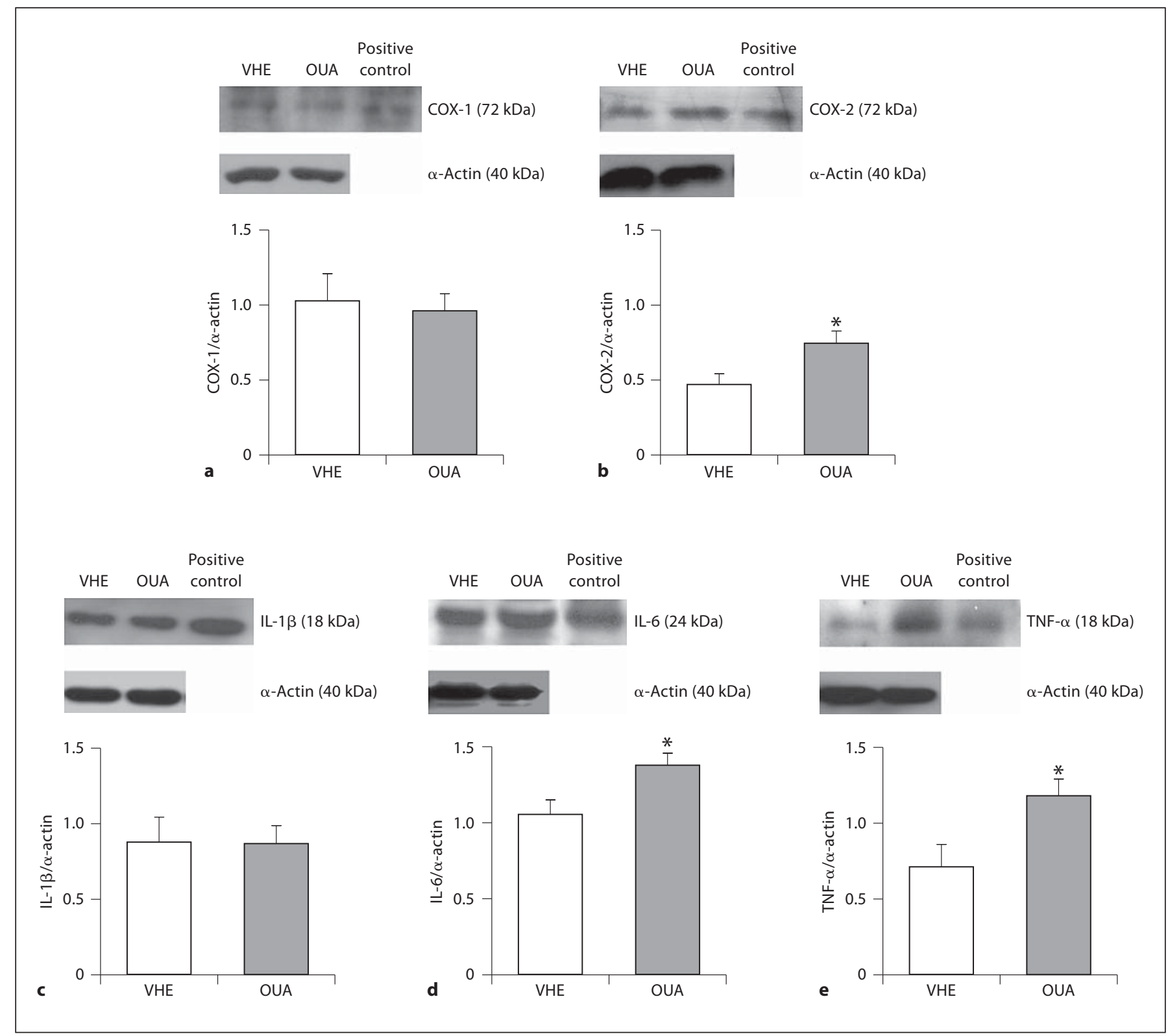

Fig. 5. Effect of ouabain treatment for 20 weeks on COX-1, COX-2, IL-1 $\beta$, IL- 6 and TNF- $\alpha$ protein expression in MRA of Wistar rats. Upper panels show representative blot for COX-1 (a), COX-2 (b), IL-1 $\beta$ (c), IL-6 (d) and TNF- $\alpha$ (e) protein expression in MRA from VHE and OUA rats. Positive control for COX-1, COX-2, IL-1 $\beta$, IL- 6 and TNF- $\alpha$ protein (lungs of rats previously activated with lipopolissacaride). Lower panel shows densitometric analysis of

[12] have also observed that 5 weeks ouabain-induced hypertension did not alter the response of MRA to noradrenaline. However, Hernanz et al. [18] suggested that 5 weeks ouabain-induced hypertension increased both basal NO and the relaxation induced by bradykinin and the Western blot for COX-1 (a), COX-2 (b), IL-1 $\beta$ (c), IL-6 (d) and TNF- $\alpha$ (e) protein expression. Results (means \pm SEM) are expressed as the ratio between the signal for COX-1, COX-2, IL-1 $\beta$, IL- 6 and TNF- $\alpha$ and the signal for their corresponding $\alpha$-actin. Number of animals used was between 5 and 7. t test: ${ }^{*} \mathrm{p}<0.05$ versus $\mathrm{VHE}$. 


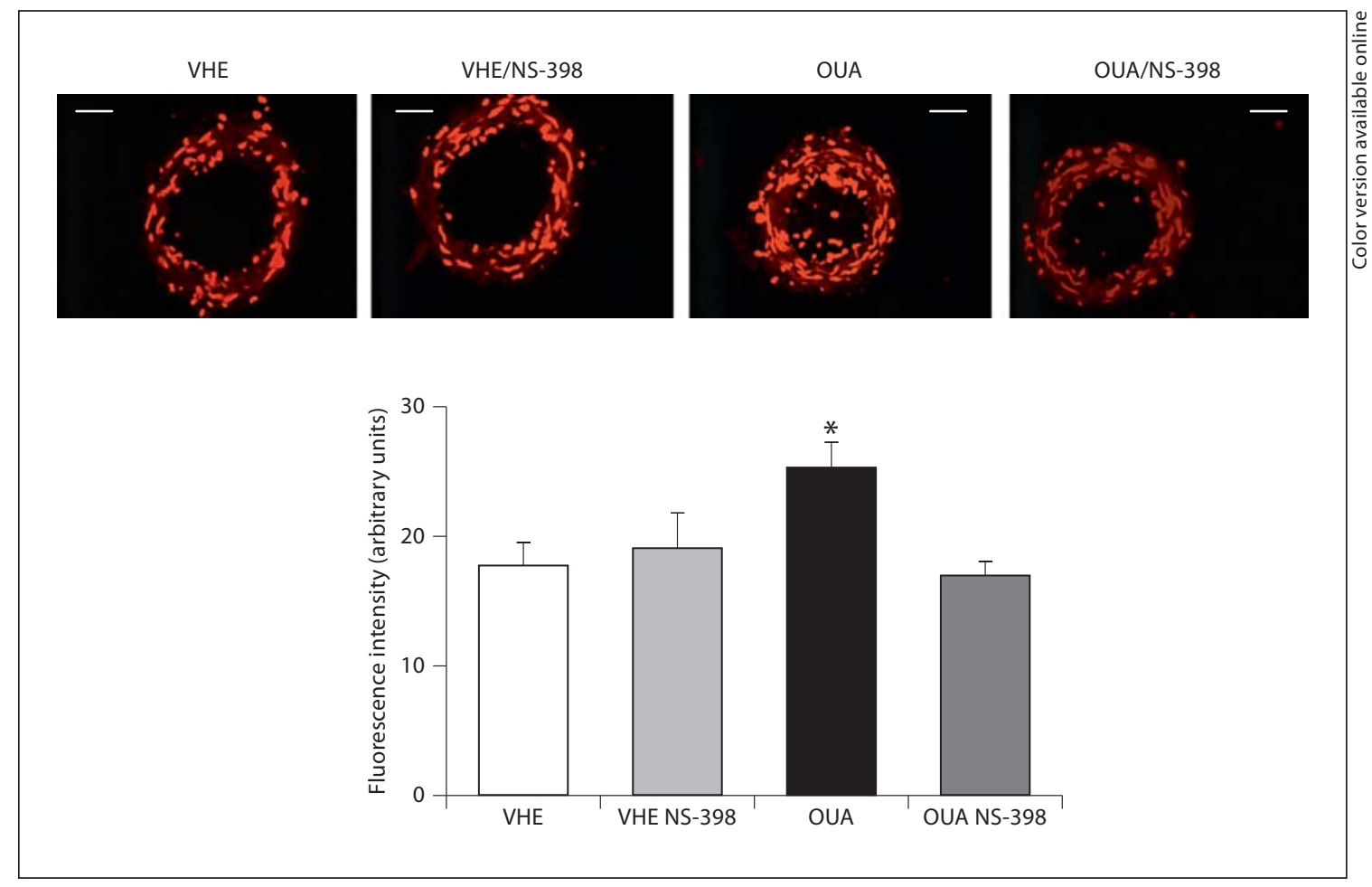

Fig. 6. Effect of ouabain treatment for 20 weeks and COX-2 inhibition (NS-398) on ROS generation in MRA of Wistar rats. Upper panel shows representative fluorescence photomicrographs of microscopic sections of MRA from VHE and OUA-treated rats for 20 weeks incubated with or without NS-398. Lower panel shows densitometric analysis of fluorescence intensity of MRA from VHE and OUA-treated rats for 20 weeks incubated with or without NS-398. Number of animals used was 4 . ANOVA (two way): ${ }^{*} \mathrm{p}<0.05$ versus VHE.

function, and also, whether these alterations differed from those observed in 5-week ouabain-treated rats. Our results demonstrate that the acetylcholine-induced relaxation was unaffected by 10 and 20 weeks of ouabain treatment, in a similar manner to vessels from 5 -week ouabain-treated rats as observed by Xavier et al. [12] and confirmed in the present study. However, constriction to noradrenaline was altered in a time-dependent manner. Thus, while 5 and 10 weeks of treatment did not alter this response, after 20 weeks of ouabain treatment the noradrenaline-induced contraction in MRA was significantly enhanced. In contrast to the present results and previous studies [14] using third-order MRA from 5-week ouabain-treated rats, Zhang et al. [25] demonstrated that fourth-order MRA from these animals exhibited augmented responses to high-dose phenylephrine. This divergence between studies may be due to the differences in the branches from mesenteric artery assessed, although in both studies the mesenteric arteries evaluated (feeder or more distal arteries) are truly resistance arter- ies, as characterized by Christensen and Mulvany [26]. Therefore, the present results suggest that longer ouabain administration enhances the vascular reactivity from MRA, which in turn may collaborate with the increased blood pressure observed in these animals.

As the endothelium plays a crucial role in the vascular effects of ouabain-induced hypertension $[9,10,12,18]$, we investigated the participation of endothelium-derived factors in the constriction to noradrenaline of resistance arteries only from 20 -week ouabain-treated rats, since no differences were observed in vascular function in shorter periods of treatment (5 and 10 weeks). Our results revealed that endothelium removal and NO synthase inhibition produced smaller increases in constriction to noradrenaline in arteries from 20 -week ouabain-treated rats compared to VHE-treated rats. The minor role of $\mathrm{NO}$ as a vasodilator may be associated with decreased synthesis and/ or bioavailability. In the current study, Western blot analysis demonstrated no change in eNOS protein expression in MRA. In line with these results, other inves- 
tigators have demonstrated that 5 weeks of ouabain treatment did not affect eNOS protein expression in MRA or cerebral arteries $[12,18]$. As eNOS protein expression remained unchanged after 20 weeks of ouabain treatment, the loss of the vasodilator effect of $\mathrm{NO}$ seems to be related to its degradation.

Under certain circumstances such as hypertension, degradation of $\mathrm{NO}$ is increased in the presence of excessive levels of superoxide anions $\left(\mathrm{O}_{2}^{\overline{2}}\right)[27,28]$, which can lead to an increased vasoconstrictor response. Aizman et al. [29] have demonstrated that low concentrations of ouabain induce cross-talk inside the cell, involving highly complex signaling cascades that lead to the formation of ROS. In line with these results, Valente et al. [30] identified $\mathrm{O}_{2}^{\overline{2}}$ as one of the ROS formed by ouabain treatment in Madin-Darby canine kidney epithelial cells. In the present study, incubation with SOD decreased noradrenaline-induced contraction in resistance arteries from 20 week ouabain-treated rats, indicating a role for $\mathrm{O}_{2}^{-}$in the augmented noradrenaline-induced contraction observed in these vessels. As SOD plus catalase did not have further effects on the response observed with SOD alone, alterations in hydrogen peroxide levels do not seem to be involved in the effects of chronic ouabain treatment. In addition, we were able to demonstrate an increase in ROS generation through oxidation of DHE in arteries from 20 -week ouabain-treated rats. As an increase in $\mathrm{O}_{\overline{2}}^{\overline{2}}$ concentration can result in enhanced inactivation of $\mathrm{NO}$ [28], these results suggest that the increased degradation of $\mathrm{NO}$ by $\mathrm{O}_{2}^{\overline{2}}$ contributes to the augmented noradrenaline response in MRA from ouabain-treated rats by 20 weeks.

Endothelial cells can also release metabolites of arachidonic acid, which are thought to contribute to the $\alpha$ adrenergic contractile response in hypertensive rats [31, 32]. Activation of thromboxane receptors allows the production of vasoconstrictor prostanoids such as prostaglandin $\mathrm{H}_{2}$ and/or thromboxane $\mathrm{A}_{2}$, which are also thought to participate in the endothelial dysfunction associated with different cardiovascular risk factors [31, 3335]. It has been reported that ouabain may induce the release of prostanoids from the vascular endothelium [36]. Moreover, Padilha et al. [19] have demonstrated that in the initial stages of chronic ouabain-induced hypertension, COX-2-derived prostanoids are involved in the modulation of the phenylephrine response in MRA. In the present study, both indomethacin, a COX-1/2 inhibitor, and NS-398, a specific COX-2 inhibitor, were able to reduce the noradrenaline response, suggesting a role for COX-2-derived prostanoids in the augmented response to noradrenaline in vessels from 20 -week ouabain-treat- ed rats. In support of these results, protein expression of COX-2, but not COX-1, was increased in MRA from this group. Furthermore, incubation with ridogrel also decreased the contractile response to noradrenaline in resistance arteries from 20 -week ouabain-treated rats, suggesting that thromboxane $\mathrm{A}_{2}$ and/or prostaglandin $\mathrm{H}_{2}$ are the major vasoconstrictor prostanoids stimulated by noradrenaline in MRA. Consistent with these results, our group has demonstrated that in spontaneously hypertensive rats treated with ouabain for 5 weeks, the response to phenylephrine in small arteries is increased and it is mainly modulated by thromboxane $\mathrm{A}_{2}$ and/or prostaglandin $\mathrm{H}_{2}$ derived from COX-2 metabolism [21].

It is now clear that COX-2 may also generate $\mathrm{O}_{2}^{-}$in some circumstances $[37,38]$. As pointed out above, the oxidative stress and COX-2 pathways are involved in the vascular damage from ouabain-treated rats. Considering these facts, we evaluated whether COX-2 could be a potencial source of $\mathrm{O}_{\dot{2}}^{-}$. Thus, we have shown that the incubation with the specific inhibitor of COX-2 decreased DHE fluorescence in arteries from 20-week ouabaintreated rats to levels similar to those observed in arteries from VHE rats. Taken together, our data strongly suggest, for the first time, that COX-2 is an important source of $\mathrm{O}_{2}^{\overline{1}}$ in ouabain-induced hypertension.

There is increasing evidence to suggest that hypertension could be considered as a chronic inflammatory disease with elevated pro-inflammatory cytokines [39] and COX-derived prostanoids, mainly from the COX-2 isoform [31]. In addition, there are reports that ouabain can stimulate signaling pathways to promote activation of inflammatory factors such as cytokines [2]. The expression of enzymes such as COX-2, iNOS and NADPH oxidase is then thought to be increased by cytokines $[38,40]$. Moreover, acute ouabain administration has been found to induce transcription of IL-1 $\beta$, IL- 6 and TNF- $\alpha$ in human peripheral blood mononuclear cells [41]. In addition, Bereta et al. [42] have shown that acute ouabain administration was able to stimulate vascular cell adhesion molecule expression in murine microvascular cells and thus provide a complementary signal to either TNF- $\alpha$ or IFN- $\gamma$ in inducing iNOS expression. Based on this evidence, and on endothelial dysfunction in MRA induced by longterm ouabain treatment, we analyzed whether 20 -week ouabain-induced hypertension was accompanied by alterations in protein expression of the pro-inflammatory cytokines IL- $1 \beta$, IL- 6 and TNF- $\alpha$. Our results demonstrate that in MRA, the protein expression of TNF- $\alpha$ and IL- 6 was enhanced. These findings therefore suggest that 20 -week ouabain-induced hypertension is characterized 
by vascular pro-inflammatory events that can contribute not only to an increased noradrenaline response, but also to advanced vascular damage in this model.

In conclusion, our findings demonstrate for the first time that chronic treatment with low doses of ouabain for 10 and 20 weeks induces a maintained mild hypertension. Nevertheless, only after 20 weeks of ouabain treatment was damage in the vascular function observed, which can be related to COX-2-derived prostanoids, oxidative stress and reduced NO bioavailability. Additionally, the injury in vascular function is associated with an increase in pro-inflammatory cytokines. Accumulating evidence from experimental and clinical trials support the notion that endogenous ouabain may play an important role in hypertension, which is associated to altera- tions in vascular function. Therefore, it seems reasonable to assume that an antihypertensive drug able to antagonize the effects of ouabain could represent a novel therapeutic approach, as described by Ferrari et al. [43].

\section{Acknowledgements}

We gratefully acknowledge Natasha Hausman for her helpful suggestions in the preparation of the article. This work was supported by grants from Fundação de Amparo à Pesquisa do Estado de São Paulo (FAPESP) and Conselho Nacional de Desenvolvimento Científico e Tecnológico (CNPq). C.F.W. was supported by a master degree fellowship award from FAPESP; A.P.D. was supported by a PhD fellowship award from CNPq. L.V.R. is a research fellow from CNPq.

\section{References}

1 Laredo J, Hamilton BP, Hamlyn JM: Ouabain is secreted by bovine adrenocortical cells. Endocrinology 1994;135:794-797.

- 2 Schoner W, Scheiner-Bobis G: Endogenous and exogenous cardiac glycosides: their roles in hypertension, salt metabolism, and cell growth. Am J Physiol 2007;293:C509-C536.

-3 Bagrov AY, Shapiro JI: Endogenous digitalis: pathophysiologic roles and therapeutic applications. Nat Clin Pract Nephrol 2008;4: 378-392.

4 Blaustein MP, Zhang J, Chen L, Song H, Raina $\mathrm{H}$, Kinsey SP, Izuka M, Iwamoto $\mathrm{T}$, Kotlikoff MI, Lingrel JB, Philipson KD, Wier WG and Hamlyn JM: The pump, the exchanger, and endogenous ouabain. Hypertension 2009;53:291-298

-5 Overbeck HW, Pamnani MB, Akera T, Brody TM, Haddy FJ: Depressed function of a ouabain-sensitive sodium-potassium pump in blood vessels from renal hypertensive dogs. Circ Res 1976;38:48-52.

-6 Hamlyn JM, Ringel R, Schaeffer J, Levinson PD, Hamilton BP, Kowarski AA, Blaustein MP: A circulating inhibitor of $\left(\mathrm{Na}^{+} \mathrm{K}^{+}\right)$ ATPase associated with essential hypertension. Nature 1982;300:650-652.

7 Yuan CM, Manuta P, Hamlyn JM, Chen S, Bohen E, Yeun J, Haddy FJ, Pammani MB: Long-term ouabain administration produces hypertension in rats. Hypertension 1993; 22:178-187.

8 Kimura K, Manunta P, Hamilton BP, Hamlyn JM: Different effects of in vivo ouabain and digoxin on renal artery function and blood pressure in the rat. Hypertension Res 2000;23:67-76.
-9 Rossoni LV, Salaices M, Marín J, Vassallo DV, Alonso MJ: Alterations in phenylephrine-induced contractions and the vascular expression of $\mathrm{Na}^{+}, \mathrm{K}^{+}$-ATPase in ouabain-induced hypertension. Br J Pharmacol 2002; 135:771-781.

10 Rossoni LV, Salaices M, Miguel M, Briones, AM, Barker LA, Vassallo DV, Alonso MJ: Ouabain-induced hypertension is accompanied by increases in endothelial vasodilator factors. Am J Physiol Heart Circ Physiol 2002;283:H2110-H2118.

11 Xavier FE, Salaices M, Marquez-Rodas I, Alonso MJ, Rossoni LV, Vassallo DV, Balfagón G: Neurogenic nitric oxide release increases in mesenteric arteries from ouabain hypertensive rats. J Hypertens 2004;22:949957.

12 Xavier FE, Rossoni LV, Alonso MJ, Balfagón G, Vassallo DV, Salaices M: Ouabain-induced hypertension alters the participation of endothelial factors in $\alpha$-adrenergic responses differently in rat resistance and conductance mesenteric arteries. Br J Pharmacol 2004; 143:215-225

-13 Xavier FE, Yogi A, Callera GE, Tostes RC, Alvarez Y, Salaices M, Alonso MJ, Rossoni LV: Contribution of the endothelin and reninangiotensin systems to the vascular changes in rats chronically treated with ouabain. $\mathrm{Br} J$ Pharmacol 2004;143:794-802.

14 Briones AM, Xavier FE, Arribas SM, González MC, Rossoni LV, Alonso MJ, Salaices $\mathrm{M}$ : Alterations in structure and mechanics of resistance arteries from ouabain induced hypertensive rats. Am J Physiol Heart Circ Physiol 2006;291:H193-H201.

-15 Huang BS, Huang X, Harmsen E, Leenen FHH: Chronic central versus peripheral ouabain, blood pressure, and sympathetic activity in rats. Hypertension 1994;23:1087-1090.

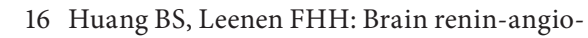
tensin system and ouabain induced sympathetic hyperactivity and hypertension in Wistar rats. Hypertension 1999;34:107-112.

17 Di Filippo C, Filippelli A, Rinaldi B, Piegari E, Esposito F, Rossi F, D’Amico M: Chronic peripheral ouabain treatment affects the brain endothelin system of rats. J Hypertens 2003;21:747-753.

-18 Hernanz R, Briones AM, Nartin A, Beltrán AE, Tejerina T, Salaices M, Alonso MJ: Ouabain treatment increases nitric oxide bioavailability and decreases superoxide anion production in cerebral vessels. J Hypertens 2008;26:1944-1954.

19 Padilha AS, Peçanha FM, Vassallo DV, Alonso MJ, Mercedes S: Ouabain treatment changes the role of endothelial factors in rat resistance arteries. Eur J Pharmacol 2008; 600:100-116.

20 Cao C, Payne K, Lee-Kwon W, Zhang Z, Lim SW, Hamlyn J, Blaustein MP, Kwon HM, Pallone TL: Chronic ouabain treatment induces vasa recta endothelial dysfunction in the rat. Am J Physiol Renal Physiol 2009; 296:F98-F106.

21 Xavier FE, Davel AP, Fukuda LE, Rossoni LV: Chronic ouabain treatment exacerbates blood pressure elevation in spontaneously hypertensive rats: the role of vascular mechanisms. J Hypertens 2009;27:1233-1242.

22 Mulvany MJ, Halpern W: Mechanical properties of vascular smooth cells in situ. Nature 1977:260:617-619.

23 Davel AP, Kawamoto EM, Scavone C, Vassallo DV, Rossoni LV: Changes in vascular reactivity following administration of isoproterenol for 1 week: a role for endothelial modulation. Br J Pharmacol 2006;148:629639. 
-24 Manunta P, Hamilton J, Rogowski AC, Hamilton BP, Hamlyn JM: Chronic hypertension induced by ouabain but not digoxin in the rat: antihypertensive effect of digoxin and digitoxin. Hypertens Res 2000;23(suppl): S77-S85.

-25 Zhang J, Hamlyn JM, Karashima E, Raina H, Mauban JRH, Izuka M, Berra-Romani R, Zulian A, Wier G, Blaustein M: Low-dose ouabain constricts small arteries from ouabain-hypertensive rats: implications for sustained elevation of vascular resistance. Am J Physiol Heart Circ Physiol 2009;297:H1140H1150.

26 Christensen KL, Mulvany MJ: Location of resistance arteries. J Vasc Res 2001;38:1-12.

-27 Rubanyi GM, Vanhoutte PM: Oxygen-derived free radicals, endothelium, and responsiveness of vascular smooth muscle. Am J Physiol 1986;250:H815-H821.

-28 Touyz RM: Reactive oxygen species, vascular oxidative stress, and redox signaling in hypertension: what is the clinical significance? Hypertension 2004;44:248-252.

-29 Aizman O, Uhlén P, Lal M, Brismar H, Aperia A: Ouabain, a steroid hormone that signals with slow calcium oscillations. Proc Natl Acad Sci USA 2001;98:13420-13424.

-30 Valente RC, Capella LS, Monteiro RQ, Rumjanek VM, Lopes AG, Capella MAM: Mechanisms of ouabain toxicity. FASEB J 2003;17: 1700-1702.
31 Alvarez Y, Briones AM, Balfagón G, Alonso MJ, Salaices M: Hypertension increases the participation of vasoconstrictor prostanoids from cyclooxygenase- 2 in phenylephrine responses. J Hypertens 2005;23:767-777.

32 Vanhoutte PM, Feletou M, Taddei S: Endothelium-dependent contractions in hypertension. Br J Pharmacol 2005;144:449-458.

33 Lüscher TF, Vanhoutte PM: Endotheliumdependent contractions to acetylcholine in the aorta of the spontaneously hypertensive rat. Hypertension 1986;8:344-348.

34 dos Santos L, Xavier FE, Vassallo DV, Rossoni LV: Cyclooxygenase pathway is involved in the vascular reactivity and inhibition of the $\mathrm{Na}^{+}, \mathrm{K}^{+}$-ATPase activity in the tail artery from L-NAME-treated rats. Life Sci 2003;74: 613-627.

35 Xavier FE, Aras-López R, Arroyo-Villa I, Campo LD, Salaices M, Rossoni LV, Ferrer M, Balfagón G: Aldosterone induces endothelial dysfunction in resistance arteries from normotensive and hypertensive rats by increasing thromboxane A2 and prostacyclin. Br J Pharmacol 2008;154:1225-1235.

36 Nakagawa M, Takamatsu H, Toyoda T, Sawada S, Tsuji H, Ijichi H: Effect of inhibition of $\mathrm{Na}^{+}, \mathrm{K}^{+}$-ATPase on the prostacyclin generation of cultured human vascular endothelial cells. Life Sci 1987;40:351-357.
37 Hernanz R, Briones AM, Alonso MJ, Vila E, Salaices M: Hypertension alters role of iNOS, COX-2, and oxidative stress in bradykinin relaxation impairment after LPS in rat cerebral arteries. Am J Physiol Heart Circ Physiol 2004;258:H225-H234.

38 Vila E, Salaices M: Cytokines and vascular reactivity in resistance arteries. Am J Physiol Heart Circ Physiol 2005;288:H1016-H1021.

>39 Virdis A, Schiffrin EL: Vascular inflammation: a role in vascular disease in hypertension? Opin Nephrol Hypertens 2003;12:181187.

40 Nedeljkovic ZS, Gokce N, Loscalzo J: Mechanisms of oxidative stress and vascular dysfunction. Postgrad Med J 2003;79:195-200.

$>41$ Matsumori A, Ono K, Nishio R, Igata H, Shioi T, Matsui S, Furukawa Y, Iwasaki A, Nose Y: Modulation of cytokine production and protection against lethal endotoxemia by the cardiac glycoside ouabain. Circulation 1997;96:1501-1506.

$\checkmark 42$ Bereta J, Cohen MC, Bereta M: Stimulatory effect of ouabain on VCAM-1 and iNOS expression in murine endothelial cells: involvement of NF-кB. FEBS Lett 1995;377:21-25.

43 Ferrari P, Torielli L, Ferrandi M, Padoani G, Duzzi L, Florio M, Conti F, Melloni P, Vesci L, Corsico N, Bianchi G: PST2238: a new antihypertensive compound that antagonizes the long-term pressor effect of ouabain. J Pharmacol Exp Ther 1998;285:83-94. 